\title{
Paracelso e as fronteiras da ciência
}

\section{Paracelsus and the frontiers of science}

\author{
Marcelo Raphael Rocha Bichara \\ Programa de Pós-Graduação em História das Ciências e das Técnicas e Epistemologia \\ (HCTE), Universidade Federal do Rio de Janeiro (UFRJ). \\ marcelorrbichara@gmail.com. \\ https://orcid.org/0000-0003-4589-3124
}

\section{Carlos Benevenuto Guisard Koehler}

Programa de Pós-Graduação em História das Ciências e das Técnicas e Epistemologia (HCTE), Universidade Federal do Rio de Janeiro (UFRJ). cbgk@uol.com.br

Resumo. A obra e a biografia do médico renascentista suíço Philip TheophrastusBombast Von Hohenheim, mais conhecido pelo pseudônimo de Paracelso (1493 - 1541), ainda permanece obscura aos olhos do pensamento moderno. Este artigo traça um esboço da sua importância filosófica para as ciências médicas, relacionando-o com autores mais contemporâneos, como C. G. Jung, Gregory Bateson e outros. Nosso objetivo está em analisar a importância histórica da medicina paracélsica, buscando entender sua relevânciacrescente para o momento atual, em especial para as ciências da vida e da saúde.

Palavras-chave: Psicossomática. Dualismo. Mecanicismo. Holismo. Paracelso.

Abstract.The work and biography of the Swiss Renaissance doctor Philip Theophrastus Bombast Von Hohenheim, better known by the pseudonym of Paracelsus (1493 - 1541), remains obscure in the eyes of modern thought. This article traces an outline of itsphilosophical importance for the medical sciences, relating him with more contemporary authors as C. G. Jung, Gregory Bateson and others. Our objective is to analyze the historical importance ofparacelsic medicine, seeking to understand its growing relevance for the currentmoment, especially inmedicine, psychology and biology.

Keywords: Psychosomatics. Dualism. Mechanism. Holism. Paracelsus. 
Recebido: 01/10/2017 Aceito: 27/10/2017 Publicado: 05/11/2017

\section{Introdução}

A historiografia tradicional costuma mencionar a obra de Nicolau Copérnico e os estudos de anatomia humana de Andreas Vesalius como os grandes marcos da ciência renascentista. No entanto, segundo Ball (2009), nenhum desses autores sãorealmente representativos do meio acadêmico e intelectual daquele tempo, apesar da óbvia contribuição que proporcionaram para as gerações seguintes. A obra de Paracelso, por outro lado, nos apresenta uma visão mais precisa do ponto em que estava o desenvolvimento da ciência em meados do século XVI:

Foi sua visão, mais do que as reformas de Copérnico e Vesalius, que desafiou as certezas equivocadas e enrijecidas de fins da Idade Média, com suas interpretações dogmáticas e tacanhas das idades clássicas sobre o universo. [...] Se quisermos compreender o que, de fato, os filósofos debatiam naqueles tempos, e medir a temperatura real da fermentação intelectual da época de Lutero e da Contrarreforma, é melhor investigar a vida de Paracelso. Podemos genuinamente toma-lo como um prisma do seu tempo: decompondo diante de nosso olhos, como eram de fato, os paradoxos, horrores e tensões que existiam entre a filosofia natural, a religião, o humanismo e a política. (BALL, 2009, p. 2)

Paracelso é conhecido como um dos grandes magos e pensadores místicos do renascimento, ao mesmo tempo em que é celebrado como o pai da farmacologia moderna e um dos pioneiros da medicina ocidental. É precisamente este aparente paradoxo que o torna um personagem tão interessante na história da ciência, um ícone marcante do processo radical e paulatino de transformação da mentalidade europeia. Tendo um pé na magia e outro na ciência, nem bruxo nem médico, um puro vir a ser em estado de metamorfose - Paracelso "ainda é um animista [...] e, no entanto, já é um materialista" (JUNG, 2011, p. 7).

Ele é um embaraço porque debocha da convicção já profundamente arraigada tanto em cientistas como historiadores, de que a história das ideias deve ser colocada em uma narrativa ordenada e unidirecional. [...] Se lutamos contra ele é porque não conseguimos evitar uma luta contra a sua época, em que pessoas faziam perguntas diferentes e enfrentavam dilemas diferentes dos nossos. Essas lutas nos dizem que o nascimento do mundo moderno não foi fácil e nem indolor, mas turbulento, violento, confuso. (BALL, 2009, p. 12)

Devido ao complexo emaranhado de contradições e conflitos em que está enredado, Paracelso continua sendo o único entre os maiores pensadores da revolução científica que ainda não foi completamente absorvido pelo conhecimento moderno, permanecendo iconoclasta e marginal (BALL, 2009, p. 11). 


\section{O animismo de Paracelso e a medicina holística}

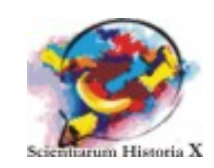

Um estudo das controvérsias passadas é particularmente esclarecedor, se os argumentos e as objeções forem analisados em termos do nosso conhecimento atual (MAYR, 1998, p. 25).

Um dos autores mais importantes para guiar nossa investigação da obra de Paracelso é outro médico suíço, o psiquiatra Carl Gustav Jung (1875 - 1961), que considera a si próprio herdeiro da medicina do mestre renascentista, dedicando décadas de estudo à sua obra, tecendo uma vasta pesquisa sobre a tradição dos alquimistas e sua relevância para a medicina contemporânea.Segundo Jung (2011, p. 11), Paracelso viu nascer de perto uma nova medicina à medida que as universidades tomavam para si "a arte dos barbeiros e cirurgiões de campanha, junto com a das parteiras, bruxas, feiticeiras, astrólogos e alquimistas". Sendo Paracelso um dos pioneiros nesta nova fase do conhecimento médico erudito, aplicou seus conhecimentos de alquimia na fabricação dos primeiros remédios químicos da história (que não eram à base de plantas ou animais), o que lhe rendeu fama e respeito internacionais.

"Se o sonho químico da alquimia se tornou realidade, PARACELSO então realmente previu a medicina química de hoje" (JUNG, 2011, p. 21 [capitular do autor]).Mas o motivo pelo qual o médico alquimista extraía remédio das pedras e metais não era porque acreditava, como os modernos, que o corpo humano fosse tão material quanto o "mundo inanimado", mas justamente o contrário: em sua visão de mundo toda a natureza era viva, animada por um "espírito" que podia ser extraído das coisas, conservado numa garrafa, num comprimido ou num unguento, sendo transportado assim com maior facilidade.

Ao invés de uma matéria inerte e passiva, concepção que predominaria na mentalidade europeia nos séculos seguintes a partir de Descartes, Paracelso propõe uma versão materialista do pan-psiquismo primitivo, onde toda a natureza é vista em seu conjunto como um agregado de matéria viva, animada por uma substância invisível e sutil, omysteriummagnumdo cosmosque ele chama de anima mundi - o princípio inteligente que conecta as partes ao todo. Uma ideia já presente entre os estoicos e os pré-socráticos e que ganha vida nova nos escritos do médico.

Rompendo com o pensamento antigo e medieval (onde explicações pontuais para fenômenos particulares eram suficientes),Paracelso inaugura a busca da ciência moderna por um sistema integrado da natureza, de onde o conhecimento médico e suas aplicações são deduzidos racionalmente de uma cosmovisão mais geral (BALL, 2009, p. 7).

Além de sua inegável contribuição para a ciência farmacológica, Jung atribui a Paracelso uma inovação filosófica de extrema importância clínica, que permaneceu marginal na história da ciência até meados do século XIX, quando o romantismo alemão redescobriu suas teorias e conferiu a ele um lugar de destaque entre os grandes nomes da Renascença: 
Para ele, homem e mundo são um agregado vivo de matéria, uma concepção que mantém afinidade com o ponto de vista científico do final do século XIX. Há, porém, uma diferença: PARACELSO ainda não pensa mecanicamente, em termos de matéria química inerte, mas de maneira animista primitiva. A natureza, para ele, ainda é povoada de bruxas, íncubos, súcubos, diabos, sílfides e ondinas. Para ele, a vivência psíquica é, ainda, uma vivência da natureza. A morte psíquica do materialismo científico ainda não o atingiu, mas ele está preparando o caminho para esse fim. (JUNG, 2011, p. 7 [grifos do autor])

\section{A ascensão do mecanicismo e o esquecimento moderno}

O sucesso estrondoso do paradigma mecanicista arrastou para debaixo do tapete todas as visões de mundo alternativas que estavam em disputa na revolução científica, obscurecendo e distorcendo até mesmo autores fundamentais como Isaac Newton, cuja visão alquímica da natureza não se encaixava no paradigma dualista cartesiano dominante, apesar da eficácia avassaladora de seus modelos matemáticos (WESTFALL, 1989). Curiosamente, foi justamente o sucesso da física newtoniana que selou a vitória do pensamento mecanicista, extirpando da matéria qualquer propriedade mental, reservando a mente apenas aos processos do pensamento humano, único ente dotado de "alma", no sentido moderno cristão (ABRANTES, 1998).

A filosofia moderna é fundada assim numa passagem do paradigma animista pagão para o paradigma mecanicista tipicamente cristão, ignorando "de maneira generalizada, nas discussões sobre ciência daqueles séculos, que outras ciências também já existiam. Em vez disso, essas outras ciências foram espremidas para dentro do quadro conceitual da física" (MAYR, 2005, p. 30).

O fisicalismo extremo (incluindo o determinismo e o extremo reducionismo), que prevalecia no pensamento ocidental após a revolução científica, influenciou fortemente a formação teórica em biologia, por vários séculos, muitas vezes, inclusive exatamente contra aquilo que hoje é evidente (MAYR, 1998, p.18).

É nesse sentido que Thomas Kuhn (2001) chama atenção para os perigos de um compromisso paradigmáticode nivel elevado. $\mathrm{O}$ apego excessivo a determinadas crenças e visões de mundo, difundidas no meio científico numa dada época, embora ajude a manter o foco do desenvolvimento científico, pode levar a comunidade científica a descartar acriticamente toda uma gama nova de possibilidades.

No entanto, é inadmissível adotar a posição de Kuhn (2001) a respeito da incomensurabilidade dos paradigmas e a definição de ciência madura pelo critério de adesão a um único paradigma. Nesses pontos concordamos com Lakatos (1979), que defende a maturidade científica como a competição colaborativa entre diferentes os paradigmas. Em seus próprios termos, deveríamos dizer que o progresso científico depende justamente da saudável concorrência entre diferentes programas de pesquisa. 
Entendemos que a história da medicina e das ciências da vida podem ser descritas como a competição entre dois programas de pesquisa distintos, um de viés mecanicista, que pensa o corpo de forma exclusivamente material, e outro mais holístico ou psíquico, que insere a mente no processo da vida.

Nossa hipótese é que o programa de pesquisa que leva os processos mentais e simbólicos em consideração tem, nos termos de Lakatos (1979), maior poder heurístico que a medicina mecanicista, pois não descarta ou exclui as causas mecânicas (físicoquímicas), somando a essas, novos fatores que são negligenciados no outro programa.

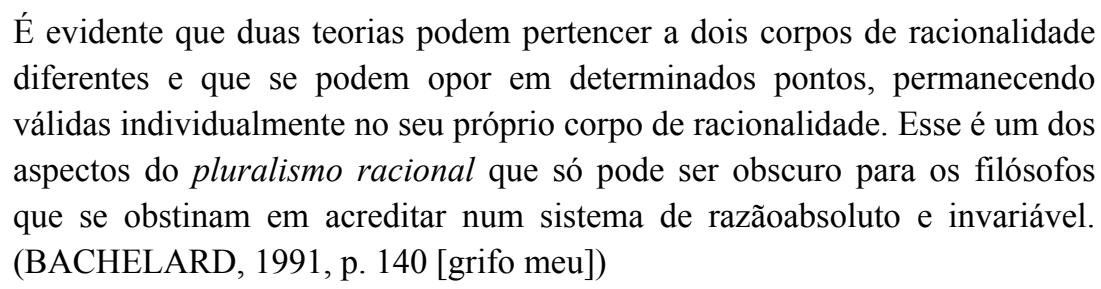

Ernest Mayr (1998), um dos pais da síntese moderna da biologia, critica a imposição da física como paradigma de ciência por autores como Popper e Kuhn, argumentando que todas as tentativas de circunscrever o mundo vivo às leis da física e descrevê-lo matematicamente falharam, porque os organismos vivos são sistemas complexos autoorganizados, afetados durante bilhões de anos por processos históricos onde o acaso e a aleatoriedade desempenham papel fundamental.

Nos termos de Maturana e Varela (1995), os organismos vivos possuem um determinismo estrutural, onde uma alteração no meio não contém necessariamente uma especificação de seus efeitos no ser vivo, mas sim é a sua própria estrutura que determina sua mudança frente a tal perturbação. Segundo os autores, o traço característico dos seres vivos é a autopoiese, isto é, a produção de si mesmo numa estrutura que determina uma estrutura que determina uma estrutura... numa rede de relações entre relações. As chamadas máquinas autopoiéticas, diferente dos corpos mecânicos, são autônomas, na medida em que constantemente subordinam suas mudanças à conservação de sua própria organização, realizando mudanças internas para compensar as perturbações externas e mantendo assim sua identidade e individualidade.

De modo semelhante, o biólogo Gregory Bateson, inspirado na cibernética, propõe a criação de uma nova epistemologia para pensar o mundo vivo. Segundo o autor, para pensar a vida é necessário levar em conta o fluxo de informação que conecta os seres entre si com o ambiente, o que permite a formação de um ecossistema complexo e autoorganizado. Segundo Bateson (1986), o materialismo e o mecanicismo tendem a ignorar as conexões de um sistema vivo, apostando numa clara separação entre as partes. Ele defende que fomos educados a pensar essas conexões como estáveis e invariáveis, como num relógio mecânico, mas que elas são na verdade como uma dança de partes que se interagem, num imbricado processo de transformações que dependem do contexto para existirem e significarem. Quando se investiga a vida, a atenção deve estar na relação 
entre as partes e seu contexto, não nas coisas em si. O que importa é o espírito que circula.

\section{Considerações finais}

De fato, para um grande número de sistemas, inanimados ou vivos, isolar todas as partes, mesmo as menores, não é suficiente para uma explicação completa. É necessário também entender a relação entre as partes, ou seja, faz-se necessária uma abordagem mais holística. (MOREIRA \& MASSONI, 2011, p. 191-192)

Gaston Bachelard (1971) nos lembra que o conhecimento científico é sempre construído histórico e socialmente, sendo setorial às diferentes ciências. Por isso é preciso analisar o passado com base nos valores do presente, pois o valor de uma ideia não depende apenas da ideia em si, mas da relação desta ideia com as outras ideias presentes no momento.

Para explicar a existência de uma enfermidade, por exemplo, é preciso considerar as relações históricas e sociocognitivas que influenciaram seu conceito. O pensamento é condicionado histórico-culturalmente. [...] Este está impregnado pelo estágio do conhecimento da época e pelo meio cultural e acaba resultando em um estilo de pensamento, ou seja, uma maneira "dirigida" de interpretar os fatos (MOREIRA \& MASSONI, 2011, p. 194 [grifo dos autores]).

Ao comparar a medicina tradicional africana com a chinesa e a indiana, Freitas (2014) argumenta que os conceitos de saúde e doença são sempre vistos como atores de um processo simbólico, onde a individualidade do paciente é tão importante na definição do diagnóstico e da terapêutica quanto a universalidade de sua condição humana. É essa singularidade do processo histórico e subjetivo de cada paciente que se perde numa medicina unicamente mecanicista, onde o corpo é dotado apenas de órgãos, células e de uma estrutura universal sem "alma" individual.

A medicina moderna não pode mais entender a alma como simples apêndice do corpo e por isso começa a levar cada vez mais em consideração o assim chamado "fator psíquico". Aproxima-se de certa forma novamente da concepção paracélsica da matéria animada pela psique, resultando daí que todo o fenômeno espiritual do próprio PARACELSO aparece sob nova luz. Como PARACELSO foi outrora o pioneiro da ciência médica, parece-nos que hoje se tornou o símbolo de uma importante modificação em nossa concepção sobre a natureza da doença e sobre a essência da vida em si. (JUNG, 2011, p. 9 [capitulares do autor])

\section{Financiamento}


O presente trabalho foi realizado com apoio da Coordenação de Aperfeiçoamento de Pessoal de Nível Superior - Brasil (CAPES) - Código de Financiamento 001.

\section{Referências}

ABRANTES, P. C. C. Imagens de natureza, imagens de ciência. Campinas: Papirus, 1998.

BACHELARD, G. A filosofia do não. Lisboa: Editorial Presença, 1991.

Epistemologia. Barcelona: Editorial Anagrama, 1971.

BALL, P. Médico do demônio: Paracelso e o mundo da magia e da ciência renascentista. Rio de Janeiro: Imago Editora, 2009.

BATESON, G. Mente e natureza: uma unidade necessária. Rio de Janeiro: Francisco Alvez, 1986.

FREITAS, V. M. A. Olhar Sobre a Recorrência da População aos Recursos AfroBrasileiros na Saúde. Belo Horizonte: Anais Eletrônicos do $14^{\circ}$ Seminário Nacional de História da Ciência e da Tecnologia, 2014.

JUNG, C. G. O espírito na arte e na ciência. Obras completas, vol. XV. Petrópolis: Vozes, 2011.

KUHN, T. A estrutura das revoluções científicas. São Paulo: Perspectiva, 2001.

LAKATOS, I. O falseamento e a metodologia dos programas de pesquisa científica. In: LAKATOS, I. e MUSGRAVE, A. (org.) A crítica e o desenvolvimento do conhecimento. São Paulo: Cultrix, 1979.

MATURANA, H.R.; VARELA, F. A árvore do conhecimento: as bases biológicas do entendimento humano. Campinas, SP: Psy II, 1995. 
MAYR, E. O desenvolvimento do pensamento biológico: diversidade, evolução e herança.Brasília: Editora da UnB, 1998.

Biologia, ciência única. São Paulo, Editora SchwarczLtda, 2005.

MOREIRA, M. A.; MASSONI, N. T. Epistemologias do século XX. São Paulo: Editora pedagógica e Universitária Ltda., 2011.

PRIGOGINE, I. O fim das certezas - Tempo, caos e leis da natureza. São Paulo: Editora UNESP, 1996.

As leis do caos. São Paulo: Editora UNESP, 2002.

WESTFALL, R. S. The construction of modern science: mechanisms and mechanics. Cambridge: Cambridge University Press, 1989. 